\title{
Controlled trial of the short- and long-term effect of psychological treatment of post-partum
}

\section{depression}

\section{Impact on maternal mood ${ }^{\dagger}$}

PETER J. COOPER, LYNNE MURRAY, ANJI WILSON and HELENA ROMANIUK

\author{
Background Psychological interven- \\ tions for postnatal depression can be \\ beneficial in the short term but their \\ longer-term impact is unknown.
}

\begin{abstract}
Aims To evaluate the long-term effect on maternal mood of three psychological treatments in relation to routine primary care.
\end{abstract}

\begin{abstract}
Method Women with post-partum depression ( $n=193$ ) were assigned randomly to one of four conditions: routine primary care, non-directive counselling, cognitive-behavioural therapy or psychodynamic therapy. They were assessed immediately after the treatment phase (at 4.5 months) and at 9 , 18 and 60 months post-partum.
\end{abstract}

Results Compared with the control, all three treatments had a significant impact at 4.5 months on maternal mood (Edinburgh Postnatal Depression Scale, EPDS). Only psychodynamic therapy produced a rate of reduction in depression (Structured Clinical Interview for DSMIII-R) significantly superior to that of the control. The benef it of treatment was no longer apparent by 9 months postpartum. Treatment did not reduce subsequent episodes of post-partum depression.

Conclusions Psychological intervention for post-partum depression improves maternal mood (EPDS) in the short term. However, this benef it is not superior to spontaneous remission in the long term.

Declaration of interest None. Funding detailed in Acknowledgements.
Post-partum depression occurs following approximately $10 \%$ of deliveries (Cooper et al, 1988; Cox et al, 1993; O'Hara \& Swain, 1996). Although the disorder tends to remit spontaneously after 4-6 months (O’Hara, 1997), it causes considerable distress and disruption to the women and their families (O'Hara, 1997), and the delivery of effective treatment is considered a priority. Well-controlled research trials have revealed that post-partum depression responds to treatment in the short term (Holden et al, 1989; Wickberg \& Hwang, 1996; Appleby et al, 1997; O'Hara et al, 2000), with treatment roughly doubling the spontaneous recovery rate. However, it is unclear whether this short-term effect is maintained and it is not clear whether different forms of psychological intervention might have different impacts. In order to address these questions, a controlled treatment trial was conducted in which three forms of brief psychological intervention, delivered to a community sample of women with post-partum depression, were compared with routine primary care, and the women were followed up on four occasions until 5 years post-partum.

\section{METHOD}

\section{Source of sample}

A large consecutive series of primiparous women (i.e. 3222), identified through the birth records of Addenbrooke's Hospital, Cambridge, was screened between January 1990 and August 1992 for mood disturbance in the early post-partum period by means of a postal administration of the Edinburgh Postnatal Depression Scale (EPDS; Cox et al, 1987). Those with suspected post-partum depression (EPDS score of 12 or more) were assessed systematically and those found to be suffering from post-partum depression were invited

†See part 2, pp. 420-427, this issue to take part in a study in which 'different forms of help to mothers' were being compared.

\section{Inclusion/exclusion criteria}

Women were considered eligible for the study if they fulfilled the following criteria: primiparous, living within a 15 -mile radius of the maternity hospital and with English as their first language. Women were excluded if they had delivered prematurely (before 36 weeks' gestation), if their infant had any gross congenital abnormality, if they had not had a singleton birth or if they were intending to move out of the area within the period of the intervention.

\section{Treatment groups}

The women were assigned to one of four conditions.

(a) Routine primary care, involving the normal care provided by the primary health care team (i.e. general practitioners and health visitors) with no additional input (apart from assessment) from the research team. This is the control condition of the trial.

(b) Cognitive-behavioural therapy (CBT), in which a range of techniques (Hawton et al, 1989) was used in the context of an appropriately modified form of the interaction guidance treatment described by McDonough (1993). The treatment was primarily directed not at the maternal depression itself but at problems identified by the mother in the management of her infant (concerning, for example, feeding or sleeping), as well as at observed problems in the quality of the mother-infant interaction. In the context of a supportive therapeutic relationship, the mother was provided with advice about managing particular infant problems, was helped to solve such problems in a systematic way, was encouraged to examine her patterns of thinking about her infant and herself as a mother, and was helped through modelling and reinforcement to alter aspects of her interactional style.

(c) Psychodynamic therapy using the treatment techniques described by Cramer \& Stern (Cramer et al, 1990; Stern, 1995), in which an understanding of the mother's representation of her infant and her relationship with her infant was promoted by exploring 
aspects of the mother's own early attachment history.

(d) Non-directive counselling, replicating the treatment provided in the Edinburgh study by Holden et al (1989), in which women were provided with the opportunity to air their feelings about any current concerns, such as marital problems or financial difficulties, as well as concerns they might raise about their infant.

The three active intervention arms of the trial were selected to determine whether treatments that focused (in different ways) on the mother-infant relationship would be more advantageous than a non-specific treatment already established as being effective in alleviating low maternal mood.

Therapy was conducted in the women's own homes on a weekly basis from 8 weeks to 18 weeks post-partum. This is the same timing as the treatment delivered by Holden et al (1989), and the 8-week invitation reflects the time when post-natal depression is likely to be detected by the primary care team in the course of routine post-natal contacts.

\section{Method of allocation}

The women were allocated randomly to a treatment group by the study recruiter, who drew one of four coloured balls from a bag, the assignment of each therapy to a different coloured ball having been defined at the start of the study and maintained until the end of the recruitment period.

\section{Therapists}

There were six study therapists: a specialist in each of the three research treatments and three non-specialists (including two seconded National Health Service health visitors) who were trained in two of the treatments, which allowed for an examination of expertise effects. P.J.C. and L.M. ran weekly supervision sessions with the therapists, during which the progress of each case was reviewed and adherence to the treatment protocols was ensured.

\section{Assessments}

Mental state assessments were made at baseline (immediately after treatment), at 9 and 18 months post-partum and at 5 years, by a trained assessor unaware of the treatment group to which the women had been assigned. Maternal mood was assessed using the EPDS as a self-report measure, as well as by interview using the depression section of the Structured Clinical Interview for DSM-III-R (SCID; Spitzer et al, 1989). The content of therapy was assessed, to check for therapist adherence, using 30 items from the Therapist Rating Scale (Silove et al, 1990). Assessments also were made of the children's cognitive and emotional development and of the quality of the mother-infant relationship (see Murray et al, 2003, this issue). The first three waves of assessments were made in the women's own homes, and the fourth and fifth assessment (i.e. 18 months and 5 years post-partum) were carried out in the research unit.

\section{Data analysis}

A power analysis, based on the findings of Holden et al (1989) that 69\% of women with post-partum depression who received counselling remitted compared with $37 \%$ of controls, indicated that subsamples of 44 would be sufficient to detect a treatment effect on rates of depressive order $(5 \%$ significance level, $80 \%$ power).

Initially, the sub-scales of the questionnaire concerned with therapy adherence were analysed to establish whether they differed between the treatment groups. The distributions of the sub-scale measures were compared using the Kruskal-Wallis one-way analysis by ranks, and the differences between the treatments were calculated using the Hodges-Lehmann estimator. Pairwise comparisons, adjusted appropriately, were used to establish significant differences (Siegel \& Castellan, 1988). Linear and logistic random effects models were used to analyse the repeated measures of maternal mood (Goldstein, 1995; Diggle et al, 1996; Everitt \& Pickles, 1999). These models allow for the effect of the different therapies on maternal mood over time to be investigated, while taking account of the correlation between the repeated measures, and they also allow for covariates of interest to be controlled for. In the models, the time of each assessment visit was treated as a discrete variable.

Initially, only the baseline EPDS scores were controlled for. Further models were then fitted to explore the effect of treatment over time, after controlling for social adversity (which was thought to be unbalanced between the treatment groups and related to maternal mood) and other baseline covariates. Several other factors thought to influence maternal mood were investigated, including infant gender and maternal age (under 25 years defined as young) and education level (up to ' $\mathrm{O}$ ' level or GCSE defined as low). In addition, two derived background variables - negative orientation to motherhood and social adversity were investigated, as suggested by previous research (Murray et al, 1996). These were derived from factors assessed antenatally (i.e. the former from previous termination of pregnancy, an unplanned pregnancy, poor relationship with own mother and inability to confide with own mother; the latter from low income, poor housing and being single or divorced).

Covariates were retained in the model if they reached a significance of $P<0.05$. The adjusted odds ratios from the logistic regression models were converted to approximate relative risks using the method of Zhang \& Yu (1998), because the rates of depression were common (i.e. $>10 \%$; Davies et al, 1998). Two subgroup analyses were performed: a completer analysis and an analysis to investigate the effect of level of expertise. The random effects models were fitted using Mlwin for Windows (Institute of Education, London, UK). All other analyses were performed using the SAS program package for Windows (version 8.02, SAS Institute, Cary, NC).

\section{RESULTS}

\section{Description of sample}

A total of 206 women were identified who fulfilled DSM-III-R (American Psychiatric Association, 1987) criteria for current major depressive disorder. Of these, only 13 refused to take part in the study. As can be seen from the CONSORT diagram (Fig. 1), the remaining 193 women were assigned randomly to one of four conditions. Three women refused to participate in the study after being informed of their therapy group (one assigned to CBT and two to psychodynamic therapy). Nineteen women dropped out of treatment early (i.e. they had four or fewer sessions) or moved away from the study area. Of the women identified as being eligible for the study, $171(83 \%)$ completed therapy: 42 in the non-directive counselling group, 41 in the CBT group, 40 in the psychodynamic therapy group and 48 in the control group. All of the 190 women successfully assigned to one of the four study conditions were approached for follow-up assessments at 4.5, 9 and 18 months. At 5 years, in 
addition to all the control participants, only those women who had completed therapy were approached. At 4.5 months, $89 \%$ of the women successfully assigned to a treatment condition were assessed, at 9 months this figure was $95 \%$, at 18 months it was $94 \%$ and at 5 years it was $73 \%(71 \%$ of all controls and $81 \%$ of those who completed therapy were assessed at 5 years).

\section{Demographic features}

Table 1 contains demographic information on those in the control and the treatment groups. The four groups were comparable on all the background demographic factors. They were comparable also in terms of one of the antenatal indices of interest - negative orientation to motherhood. However, there appeared to be a difference between the groups in terms of the second antenatal index of interest-marked social adversity - with more women experiencing high adversity in the control group (i.e. $35 \%$ ) and fewer women in the psychodynamic therapy group (i.e. 10\%).
Ten per cent of the women who were successfully randomly assigned did not complete the trial ( 6 from the non-directive counselling group, 1 from CBT, 8 from psychodynamic therapy and 4 from the control group). Women were considered to be completers if they attended more than four treatment sessions (for women assigned to treatment) and did not move out of the study area during the therapy period. No difference was found between the completers and non-completers on the measures of maternal mood collected pre-therapy and at 4.5, 9 and 18 months. The women who did not complete therapy were younger $($ mean $=24$ years, s.d. $=6.3$ ) than those who did complete (mean $=28$ years, $\quad$ s.d. $=5.1 ; \quad t=-2.9, \quad$ d.f. $=186$, $P=0.004)$. The non-completer group also had a higher proportion of women who were single or separated (Fisher's exact test $P=0.05$ ). The two groups were comparable in terms of level of education and the two derived background measures of orientation to motherhood and social adversity.

\section{Therapy adherence}

In order to confirm that the three treatments were being delivered as intended, the Therapist Rating Scale was administered to the women who had received one of the three index treatments. The responses to this questionnaire are summarised in Table 2, along with the median differences between treatment groups. The Kruskal-Wallis (KW) test was used to establish whether the responses to each of the six sub-scales differed between the treatment groups. A treatment effect was found for four of the sub-scales: cognitive focus $(\mathrm{KW}=24$, d.f. $=2, P<0.001)$, behavioural tasks $(\mathrm{KW}=58$, d.f. $=2, P<0.001)$, organisation $(\mathrm{KW}=28$, d.f. $=2, P<0.001)$ and relationship $(\mathrm{KW}=41, \quad$ d.f. $=2$, $P<0.001)$. Pairwise comparisons, adjusted appropriately, revealed that the women who had been assigned to the CBT group had significantly higher median responses for cognitive focus, behavioural tasks and organisation compared with the women assigned to the non-directive counselling

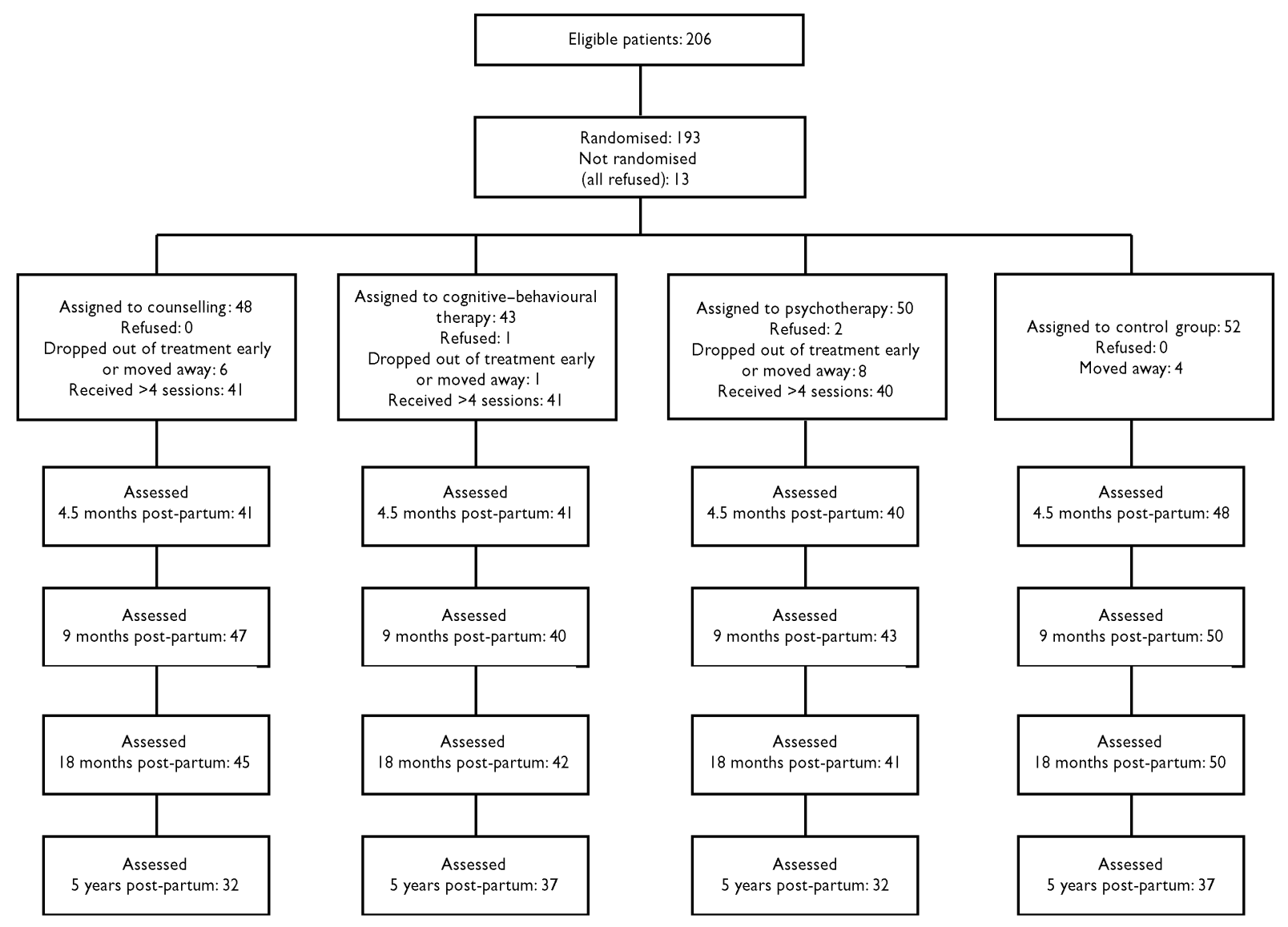

Fig. I CONSORT diagram. 
Table I Demographic characteristics of the women successfully assigned to one of the four conditions

\begin{tabular}{|c|c|c|c|c|}
\hline \multirow[t]{2}{*}{ Demographic characteristics } & \multicolumn{3}{|c|}{ Treated } & \multirow{2}{*}{$\begin{array}{c}\text { Untreated } \\
\begin{array}{c}\text { Control } \\
(n=52)\end{array}\end{array}$} \\
\hline & $\begin{array}{l}\text { Counselling } \\
\qquad(n=48)\end{array}$ & $\begin{array}{l}\text { Cognitive-behavioural } \\
\text { therapy }(n=42)\end{array}$ & $\begin{array}{l}\text { Psychodynamic } \\
\text { therapy }(n=48)\end{array}$ & \\
\hline \multicolumn{5}{|l|}{ Age, years } \\
\hline Mean (s.d.) & $28.4(5.3)$ & $27.9(5.4)$ & $28.1(5.6)$ & $26.5(5.1)$ \\
\hline Range & $20-38$ & $17-39$ & $17-42$ & $18-36$ \\
\hline \multicolumn{5}{|l|}{ Education } \\
\hline None/CSE/‘O' level/GSCE & $40 \%$ & $52 \%$ & $35 \%$ & $54 \%$ \\
\hline 'A' level/further qualification & $34 \%$ & $26 \%$ & $44 \%$ & $20 \%$ \\
\hline Degree/higher degree & $26 \%$ & $21 \%$ & $21 \%$ & $26 \%$ \\
\hline \multicolumn{5}{|l|}{ Marital status } \\
\hline Single/divorced/widowed & $11 \%$ & $14 \%$ & $6 \%$ & $17 \%$ \\
\hline Married/co-habiting & $89 \%$ & $86 \%$ & $94 \%$ & $83 \%$ \\
\hline Negative orientation to motherhood & $26 \%$ & $41 \%$ & $27 \%$ & $45 \%$ \\
\hline High social disadvantage & $30 \%$ & $24 \%$ & $10 \%$ & $35 \%$ \\
\hline
\end{tabular}

Table 2 Summary of the Therapist Rating Scale (TRS) questionnaire results

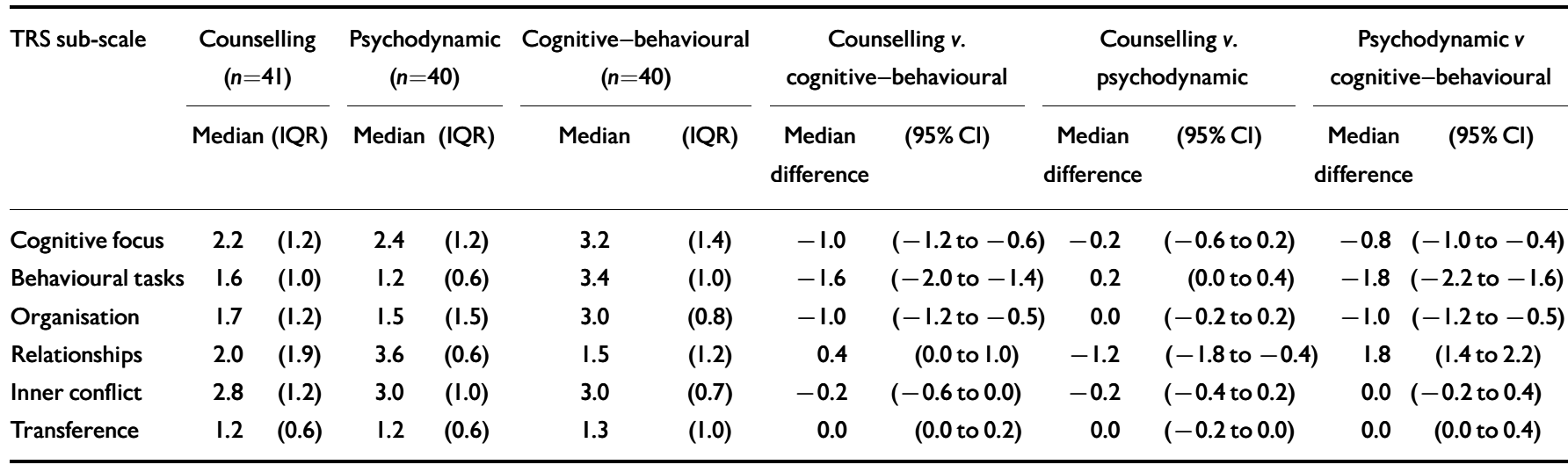

$\mathrm{IQR}$, interquartile range.

and psychodynamic therapy groups. The women who received psychodynamic therapy had a significantly higher median response on the relationship sub-scale compared with the women assigned to the non-directive counselling and the CBT groups. The inner conflict and transference sub-scales did not differ between the treatment groups.

This pattern of findings confirms that the treatments were delivered as intended.

\section{Impact of treatment on maternal mood}

\section{The Edinburgh Postnatal Depression Scale}

The EPDS scores after the treatment period are summarised in Table 3 for all women who were randomised successfully. At 4.5 months, compared with the women in the control condition, the group of women who had received any one of the three treatments had lower EPDS scores (mean difference was $-1.9 ; 95 \% \mathrm{CI}-3.5$ to -0.3 ). After 4.5 months the mean EPDS scores were similar. At 9 months the mean difference was $0.1(95 \% \mathrm{CI}-1.7$ to 1.9$)$, at 18 months it was $0.3(95 \% \mathrm{CI}-1.4$ to 2.1$)$ at 5 years it was -0.7 (95\% CI -2.8 to 1.4$)$.

From Fig. 2a, which shows the mean EPDS score by treatment condition and assessment visit, it can be seen that the mean EPDS scores were lower after the therapy period for all four groups. At 4.5 months post-partum, the women in the control group appear, from Fig. 2a, to have had a smaller decrease on average in their EPDS score than the women in the three therapy groups. This is supported by Fig. 2b, which shows that the mean percentage reduction in EPDS from baseline is much lower for the control group at 4.5 months compared with all the treatment groups. However, at 9 months post-partum, treatment appears to have produced no further reduction in the mean EPDS scores.

The random effects model for the repeatedly measured EPDS scores confirms these initial observations. At 4.5 months, after controlling for baseline EPDS, the EPDS scores were found to be significantly lower for all three treatment groups compared with the control group (see Table 3). After the 4.5-month assessment, all treatment groups were found to be comparable with the control condition.

After controlling for social adversity and level of education, the same magnitudes of effects were found.

An analysis of only the women who had successfully completed therapy produced the same findings. 
Table 3 Estimates of treatment effects using the Edinburgh Postnatal Depression Scale (EPDS): intention-to-treat analysis

\begin{tabular}{|c|c|c|c|c|c|c|c|}
\hline \multirow[t]{2}{*}{ Timing of assessment } & \multirow[t]{2}{*}{ Treatment group } & \multicolumn{3}{|c|}{ Summary statistics } & \multicolumn{3}{|c|}{ Model estimates' } \\
\hline & & $n$ & Mean & (s.d.) & Treatment effect & $P$ & $(95 \% \mathrm{Cl})$ \\
\hline \multirow[t]{5}{*}{4.5 months } & Control & 50 & 11.3 & $(4.8)$ & & & \\
\hline & All treatments & 134 & 9.4 & $(5.0)$ & -2.5 & $\leqslant 0.001$ & $(-3.9$ to -1.0$)$ \\
\hline & Counselling & 47 & 9.9 & $(5.9)$ & -2.1 & 0.02 & $(-3.8$ to -0.3$)$ \\
\hline & Psychodynamic & 45 & 8.9 & $(4.2)$ & -2.6 & 0.003 & $(-4.4$ to -0.9$)$ \\
\hline & Cognitive-behavioural & 42 & 9.2 & $(4.8)$ & -2.7 & 0.003 & $(-4.5$ to -0.9$)$ \\
\hline \multirow[t]{5}{*}{9 months } & Control & 48 & 9.2 & $(5.4)$ & & & \\
\hline & All treatments & 129 & 9.3 & $(5.5)$ & -0.3 & 0.70 & $(-2.0$ to 1.3$)$ \\
\hline & Counselling & 46 & 9.6 & $(5.8)$ & -0.2 & 0.87 & $(-3.5$ to 3.2$)$ \\
\hline & Psychodynamic & 43 & 9.5 & $(5.5)$ & 0.2 & 0.85 & $(-2.9$ to 3.3$)$ \\
\hline & Cognitive-behavioural & 40 & 8.6 & $(5.9)$ & -1.0 & 0.33 & $(-4.4$ to 2.4$)$ \\
\hline \multirow[t]{5}{*}{18 months } & Control & 48 & 8.9 & $(4.4)$ & & & \\
\hline & All treatments & 127 & 9.2 & $(5.5)$ & -0.1 & 0.94 & $(-1.7$ to 1.6$)$ \\
\hline & Counselling & 44 & 9.6 & $(5.2)$ & 0.3 & 0.79 & $(-3.1$ to 3.6$)$ \\
\hline & Psychodynamic & 41 & 9.1 & $(5.6)$ & 0.1 & 0.92 & $(-3.3$ to 3.5$)$ \\
\hline & Cognitive-behavioural & 42 & 8.9 & $(5.4)$ & -0.6 & 0.87 & $(-3.9$ to 2.8$)$ \\
\hline \multirow[t]{5}{*}{5 years } & Control & 34 & 9.9 & (5.7) & & & \\
\hline & All treatments & 92 & 9.2 & $(5.0)$ & -1.4 & 0.18 & $(-3.4$ to 0.6$)$ \\
\hline & Counselling & 33 & 8.9 & $(4.9)$ & -1.9 & 0.62 & $(-5.5$ to 1.7$)$ \\
\hline & Psychodynamic & 28 & 9.0 & $(4.5)$ & -1.4 & 0.26 & $(-5.1$ to 2.2$)$ \\
\hline & Cognitive-behavioural & 31 & 8.9 & $(5.8)$ & -0.7 & 0.56 & $(-4.4$ to 2.9$)$ \\
\hline
\end{tabular}

I. Adjusted for mean centred baseline EPDS score.

Results on the Structured Clinical Interview for DSM-III-R

At 4.5 months, $40 \%$ of the controls had remitted from depression (see Table 4). In comparison, of the 135 women who had received treatment, $61 \%$ had remitted at this time (percentage difference of $21 \%$; $95 \%$ CI 5 to $37 \%$ ). After 4.5 months the levels of remission were similar for the treated and control groups. At 9 months only $4 \%$ more of the women in the treated group had remitted compared with the control group ( $95 \% \mathrm{CI}-11$ to $19 \%$ ), at 18 months $11 \%$ less of the treated group had remitted $(95 \% \mathrm{CI}-25$ to $3 \%)$ and at 5 years $4 \%$ more of the treated women had remitted (95\% CI -11 to $21 \%$ ).

The repeated post-partum SCID measures of depression were analysed using a random effects logistic model. After controlling for baseline EPDS, at 4.5 months, compared with the controls, there was no difference in the rate of depression for the women in the non-directive therapy and the CBT groups. Compared with the control condition, psychodynamic therapy was found to be more effective in reducing the rate of depression (see Table 4). After the 4.5-month assessment, the three treatment groups were found to be not significantly different from the control condition with respect to reducing the risk of post-natal depression.

The effects of treatment remained the same after controlling for social adversity and level of maternal education.

An analysis of the outcomes of the women who had successfully completed therapy produced the same findings as those above.

\section{Expertise effects}

For women who received treatment, an expertise effect was found for maternal mood at both 4.5 months and 9 months, after controlling for type of treatment, baseline EPDS, social adversity and level of education. A significantly greater reduction in EPDS score was found for women treated by non-specialists compared with those treated by specialists at 4.5 months $(-2.1$; $95 \% \mathrm{CI}-3.7$ to $-0.5, P=0.01)$ and at 9 months $(-2.0,95 \%$ CI -4.0 to -0.1 ; $P=0.04$ ). In order to investigate further the effect of the therapists' level of expertise in relation to the control condition, six treatment categories were created: a specialist and a non-specialist group of each of the three treatments. After controlling for baseline EPDS, social adversity and level of education, all three non-specialist treatment groups were found to be significantly different from the control condition in terms of EPDS score at 4.5 months. Treatment effects at 4.5 months were estimated as -2.2 for non-specialist non-directive counselling ( $95 \% \mathrm{CI}-4.0$ to $-0.3 ; P=0.02$ ), -3.3 for non-specialist psychodynamic therapy $(95 \% \mathrm{CI}-5.4$ to $-1.1 ; P=0.003)$ and -2.4 for non-specialist CBT $(95 \% \mathrm{CI}$ -4.1 to $-0.8 ; P=0.003)$. After 4.5 months there was found to be no significant difference between the control condition and each of the non-specialist groups. At all assessments, and for all three treatments, women treated by specialists were no different from those in the control group.

For women who had received treatment, level of expertise was found to be unrelated to recovery from depressive disorder, after having controlled for type of treatment, baseline EPDS, social adversity and level of education.

\section{Subsequent post-partum depression}

Of the 138 women assessed at 5 years postpartum, a total of 98 had had a subsequent 
(a)

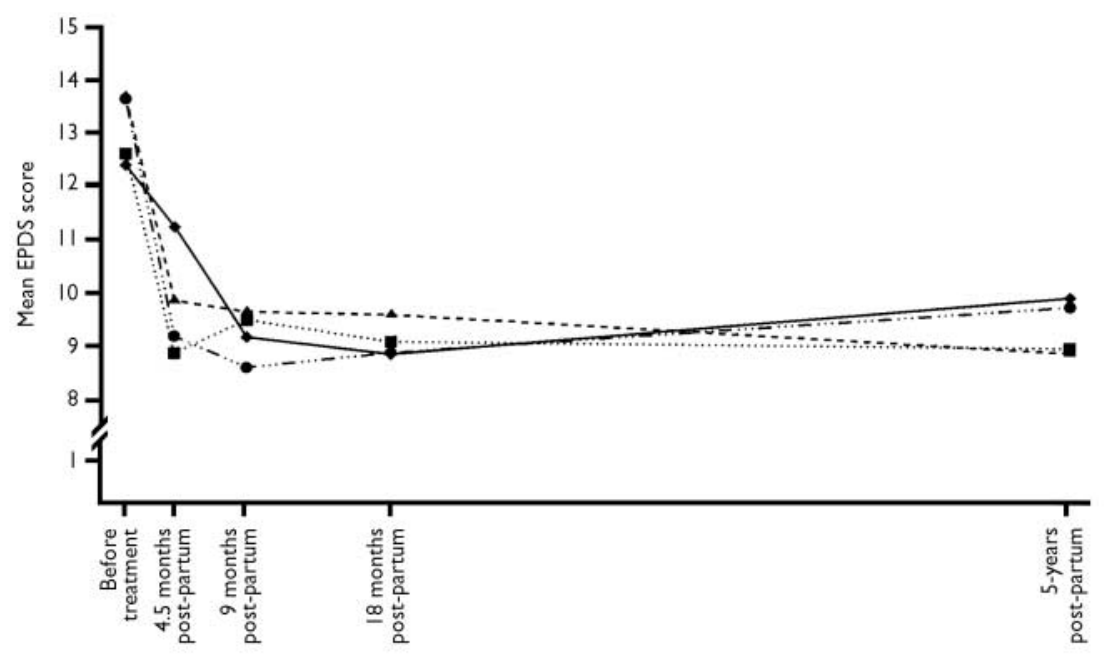

(b)

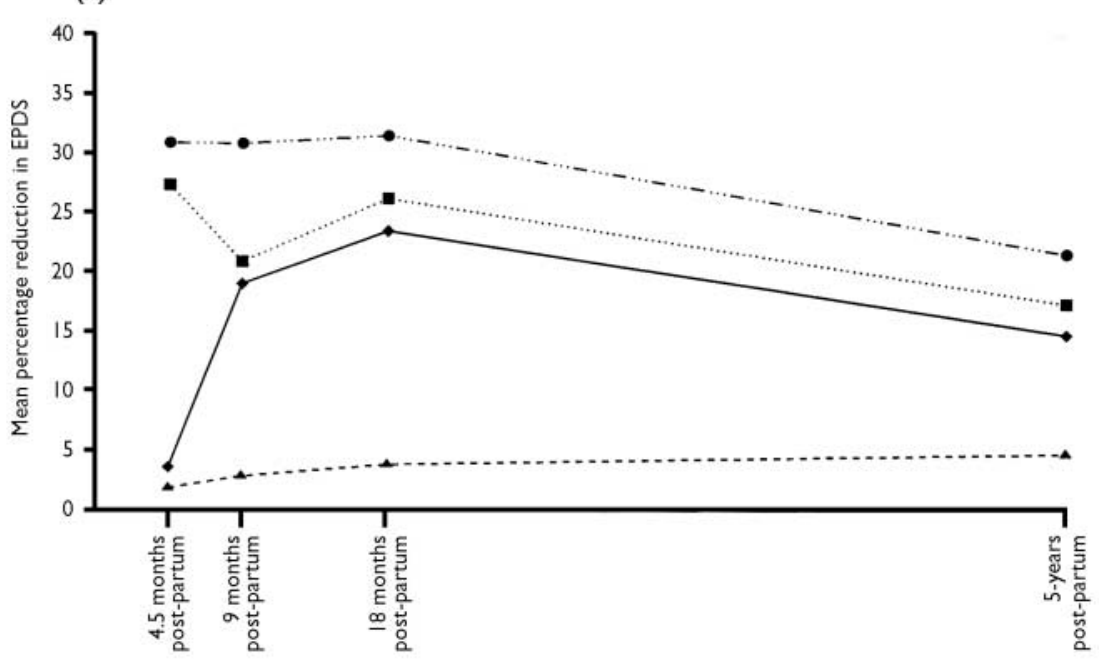

Fig. 2 The Edinburgh Postnatal Depression Scale (EPDS) scores by type of therapy and assessment visit: ( $\mathbf{\Delta})$ counselling; $(\mathbb{\square})$ psychodynamic therapy; $(\bullet)$ cognitive-behavioural therapy; $(\diamond)$ control.

delivery. At the 5-year assessment, when detailed psychiatric histories were taken, note was taken of whether any episode of depression occurred in the period immediately following subsequent deliveries. There were 27 episodes of post-partum depression subsequent to the initial episode: 20 of these occurred in women who had received treatment (i.e. 28\%) and 7 occurred in women who had received no intervention (i.e. $27 \%$ ). There was no difference between these rates (percentage difference of $1 \%$; $95 \%$ CI $-19 \%$ to $20 \%, \chi^{2}=0.01$; d.f. $\left.=1\right)$. Treatment for the initial episode of post-partum depression, therefore, did not have an impact on the risk of subsequent post-partum depression.

\section{DISCUSSION}

\section{Treatments for post-partum depression}

There have been a number of studies of both the pharmacological and psychological treatment of post-partum depression. Only one of these has been a formal trial of an antidepressant medication. Appleby et al (1997), in a factorial design involving the use of fluoxetine or placebo in combination with one or six counselling sessions, demonstrated an impressive antidepressant effect for both the active drug and the psychological treatment over a 3-month treatment period. However, there was no additive effect of the two treatments, and drug treatment was not superior to the psychological treatment. Given that, of the women with depression invited to take part in the study, less than half agreed and the main reason for refusal was 'reluctance to take medication', the role of fluoxetine, or indeed any other antidepressant medication, in the treatment of post-partum depression is likely to be limited.

In another placebo-controlled trial of a pharmacological agent (Henderson et al, 1991), treatment with oestradiol skin patches for 2 months was found to produce a greater elevation in mood than placebo; but because the patients in this study were all medical referrals, they are likely to have been a sample selected for a greater severity of depression than is typical of the population of women with post-partum depression. The extent to which the findings from this study can be generalised must, therefore, be questioned.

In contrast to the questionable clinical utility of antidepressant and hormonal treatments, several studies have found psychological forms of treatment, notably counselling, to be both highly acceptable to the women and highly effective. Thus, Holden et al (1989), in an early study of brief nondirective counselling delivered women with post-partum depression by health visitors, found the rate of recovery after 13 weeks to be twice that among those who received counselling compared with those who did not. Similar findings have been reported from a study carried out in Sweden, where child health clinic nurses delivered counselling to women with post-natal depression women (Wickberg \& Hwang, 1996).

There has been surprisingly little research interest in the application of psychological forms of treatment other than counselling in post-natal depression. Stuart \& O'Hara (1995) have advocated the use of interpersonal psychotherapy. A recent controlled trial in which interprersonal psychotherapy was compared with a waiting-list control group found a significant benefit of the index treatment in terms of maternal mood and social functioning (O'Hara et al, 2000). Its efficacy compared with other forms of treatment such as CBT or counselling is not known. Its effectiveness as a treatment delivered within the health service also is not established.

\section{Individual v. group treatment}

In the current study, the offer of psychological intervention was highly acceptable 
Table 4 Estimates of treatment effects using the Structured Clinical Interview for DSM-III-R Diagnosis (SCID): intention-to-treat analysis

\begin{tabular}{|c|c|c|c|c|c|c|}
\hline \multirow[t]{2}{*}{ Timing of assessment } & \multirow[t]{2}{*}{ Treatment group } & \multicolumn{2}{|c|}{ Summary statistics } & \multicolumn{3}{|c|}{ Model estimates ${ }^{\prime}$} \\
\hline & & $n$ & $\%$ without depression & RR & $P$ & $(95 \% \mathrm{Cl})$ \\
\hline \multirow[t]{4}{*}{4.5 months } & Control & 50 & 40 & & & \\
\hline & All treatments & 135 & 61 & 1.60 & 0.01 & $(1.14-1.98)$ \\
\hline & Counselling & 48 & 54 & 1.38 & 0.14 & $(0.82-1.89)$ \\
\hline & Cognitive-behavioural & 42 & 57 & 1.50 & 0.09 & $(0.92-1.98)$ \\
\hline \multirow[t]{5}{*}{9 months } & Control & 48 & 69 & & & \\
\hline & All treatments & 130 & 73 & 1.09 & 0.48 & $(0.83-1.26)$ \\
\hline & Counselling & 47 & 66 & 0.99 & 0.77 & $(0.33-1.36)$ \\
\hline & Psychodynamic & 43 & 79 & 1.15 & 0.28 & $(0.54-1.39)$ \\
\hline & Cognitive-behavioural & 40 & 75 & 1.12 & 0.56 & $(0.45-1.39)$ \\
\hline & All treatments & 128 & 70 & 0.87 & 0.21 & $(0.61-1.06)$ \\
\hline & Counselling & 45 & 69 & 0.87 & 0.16 & $(0.28-1.17)$ \\
\hline & Psychodynamic & 41 & 7I & 0.85 & 0.20 & $(0.25-1.17)$ \\
\hline & Cognitive-behavioural & 42 & 71 & 0.90 & 0.26 & $(0.31-I .18)$ \\
\hline \multirow[t]{5}{*}{5 years } & Control & 37 & 76 & & & \\
\hline & All treatments & 102 & 80 & 1.09 & 0.40 & $(0.62-I .22)$ \\
\hline & Counselling & 33 & 79 & 1.08 & 0.68 & $(0.48-1.28)$ \\
\hline & Psychodynamic & 33 & 79 & 1.06 & 0.79 & $(0.40-1.28)$ \\
\hline & Cognitive-behavioural & 36 & 83 & 1.13 & 0.44 & $(0.54-\mathrm{I} .28)$ \\
\hline
\end{tabular}

I. Adjusted for mean centred baseline SCID score.

to the women identified as being eligible to join the study. Indeed, very few of those offered one of the interventions refused to enter the trial, and few of those who accepted the offer of treatment dropped out. This stands in marked contrast not only to take-up rates for studies that have offered pharmacological treatment as a component of the study (Appleby et al, 1997) but also to studies in which group interventions have been offered in pregnancy and the early post-partum weeks to be vulnerable women and women with depression (Stamp et al, 1995; Buist et al, 1999; Brugha et al, 2000; Elliott et al, 2000). In fact, mothers with post-partum depression are commonly reluctant to make use of group-based mother and baby clinics run by health visitors (Seeley et al, 1996). Thus, although group-based interventions may be useful in certain subsamples of women, it seems likely that for the majority of primiparous women with post-partum depression initial support needs to be offered on a one-to-one basis.

\section{Findings of the current study at 4.5 months post-partum}

After having controlled for baseline EPDS scores, the EPDS scores at 4.5 months were found to be lower for all three treatment groups compared with the control condition. Indeed, by 4.5 months the women in all three treatment conditions had experienced a marked reduction in depressive symptoms. The lack of a significant difference in terms of remission from depressive disorder between two of the treatment conditions and the controls requires some explanation. First, the rate of recovery of those in the control condition was somewhat higher than that reported in previous studies (e.g. Holden et al, 1989; Wickberg \& Hwang, 1996). This could be attributable to the amount of attention they received in both the recruitment and assessment process. Second, the outcome of those who received non-directive counselling and CBT from a specialist was unexpectedly poor. Indeed, if only the findings from the health visitors is considered for both the non-directive counselling and the CBT conditions, the remission rate for non-directive counselling (which was $54 \%$ for all therapists) was $60 \%$, and the remission rate for CBT (which was $57 \%$ for all therapists) was $66 \%$. The likely explanation for this is that the health visitors were the only therapists within the trial who had previous experience of home visiting.

\section{Findings of the current study at 9 months post-partum}

By 9 months post-partum the positive benefit of the treatments was no longer apparent, because the spontaneous remission rate brought the women in the control group to the same point as those in the three treatment groups. Indeed, apart from the significant difference immediately following the intervention between the women who had received the treatments and those who had not, there were no differences in terms of subsequent depression between the controls and the index groups at either 9 or 18 months. At 5 years (when only those who completed treatment or had been assigned to the control condition were approached for assessment) there was still no benefit of having received the intervention. Thus, none of the treatments was related to the number of subsequent depressive episodes, post-partum or otherwise.

\section{ACKNOWLEDGEMENTS}

We are indebted to all the women and children who took part in this study. This research was carried out within the Cambridge University Department of Psychiatry. The initial trial was supported by a 
grant from Birthright. The 5-year follow-up was supported by the Medical Research Council. We are grateful to Angela Cameron, Sian Coker, Jenny Corrigal, Bridget Halnan, Sheelah Seeley and Claire Wilson for their help with carrying out the treatment, to Jill Butler, Janet Edwards, Alison Hipwell and Agnese Fiori-Cowley for their help with the assessments and to Matt Woolgar for his comments on the manuscript.

\section{REFERENCES}

American Psychiatric Association (1987) Diagnostic and Statistical Manual of Mental Disorders (3rd edn, revised) (DSM-III-R). Washington, DC: APA

Appleby, L., Warner, R., Whitton, A., et al (1997) A controlled study of fluoxetine and cognitive-behavioural counselling in the treatment of postnatal depression. BMJ, 314, 932-936.

Brugha, T. S., Wheatley, S., Taub, N. A., et al (2000) A pragmatic randomised trial of antenatal intervention to prevent post-natal depression by reducing psychosocial risk factors. Psychological Medicine, 30, 1273-1281.

Buist, A., Westley, D. \& Hill, C. (1999) Antenata prevention of postnatal depression. Archives of Women's Mental Health, I, 167-173.

Cooper, P. J., Campbell, E. A., Day, A., et al (1988) Non-psychotic psychiatric disorder after childbirth. A prospective study of prevalence, incidence, course and nature. British Journal of Psychiatry, I52, 799-806.

\section{Cox, J. L., Holden, J. M. \& Sagovsky, R. (1987)}

Detection of postnatal depression. Development of the Edinburgh Postnatal Depression Scale. British Journal of Psychiatry, I50, 782-786.

_ , Murray, D. \& Chapman, G. (1993) A controlled study of the onset, duration and prevalence of postnatal depression. British Journal of Psychiatry, 163, 27-31.

Cramer, B., Robert-Tissot, C., Stern, D., et al (1990) Outcome evaluation in brief mother-infant psychotherapy: a preliminary report. Infant Mental Health Journal, II, 278-300.

Davies, H., Crombie, I. K. \& Tavakoli, M. (1998) When can odds ratios mislead? BMJ, 316, 989-991.

Diggle, P. J., Liang, K. Y. \& Zeger, S. L. (1996) Analysis of Longitudinal Data. New York: Oxford University Press.

Elliott, S. A., Leverton, T. J., Sanjack, M., et al (2000) Promoting mental health after childbirth: a controlled trial of primary prevention of postnatal depression. British Journal of Clinical Psychology, 39, 223-24l.

Clinical implications and limitations appear at the end of Part 2, p. 427

PETER J. COOPER, DPhil, LYNNE MURRAY, PhD,Winnicott Research Unit, Department of Psychology, University of Reading, Reading, UK; ANJI WILSON, PhD, Centre for Family Research, Department of Social and Political Studies, University of Cambridge; HELENA ROMANIUK, PhD,Winnicott Research Unit, Department of Psychology, University of Reading, Reading, UK

Correspondence: Professor Peter J. Cooper, Winnicott Research Unit, Department of Psychology, University of Reading, Whiteknights, 3 Earley Gate, Reading RG6 6AL, UK

(First received 22 March 2002, final revision 5 November 2002, accepted 3 December 2002)

Everitt, B. S. \& Pickles, A. (1999) Statistical Aspects of the Design and Analysis of Clinical Trials. River Edge, NJ: World Scientific Press.

Goldstein, H. (1995) Multilevel Statistical Models. London: Edward Arnold.

Hawton, K., Salkovskis, P., Kirk, J., et al (1989) Cognitive Behavioural Approaches to Adult Psychiatric Disorders. Oxford: Oxford University Press.

Henderson, A. G., Gregoire, A. J. P., Kumar, R., et a (1991) Treatment of severe postnatal depression with oestradiol skin patches. Lancet, 338, 816-8I7.

Holden, J., Sagovsky, R. \& Cox, J. L. (1989) Counselling in a general practice setting: a controlled study of health visitor intervention in the treatment of postnatal depression. BMJ, 298, 223-226.

McDonough, S. (1993) Interaction guidance: understanding and treating early infant-caregiver relationship disorders. In Handbook of Infant Menta Health (ed. C. Zeanah), pp. 414-426. New York: Guilford Press.

Murray, L., Fiori-Cowley, A., Hooper, R., et al (1996) The impact of postnatal depression and associated adversity on early mother-infant interactions and later infant outcome. Child Development, 67, 2512-2526.

_ , Cooper, P. J., Wilson, A., et al (2003) Controlled trial of the short- and long-term effect of psychological treatment of post-partum depression. 2. Impact on the mother-child relationship and child outcome. British Journal of Psychiatry, 182, 420-427.

O'Hara, M. H. (1997) The nature of postpartum depressive disorders. In Postpartum Depression and Child Development (eds L. Murray \& P. J. Cooper), pp. 3-31. New York: Guilford.

— \& Swain, A. M. (1996) Rates and risks of postpartum depression - a meta-analysis. International Review of Psychiatry, 8, 37-54.
_ , Stuart, S., Gorman, L. L., et al (2000) Efficacy of interpersonal psychotherapy for postpartum depression. Archives of General Psychiatry, 57, 1039-1045.

Seeley, S., Murray, L. \& Cooper, P. J. (1996) The outcome for mothers and babies of health visitor intervention. Health Visitor, 69, 135-138.

Siegel, S. \& Castellan, N. J. (1988) Nonparametric Statistics for the Behavioral Sciences. New York: McGrawHill.

Silove, D., Parker, G. \& Manicavasagar, V. (1990) Perceptions of general and specific therapist behaviors. Journal of Nervous and Mental Disease, 178, 292-299.

Spitzer, R. L., Williams, J. B.W., Gibbon, M., et al (1989) Structured Clinical Interview for DSM-III-R Patient Edition (with Psychotic Screen). New York: Biometrics Research Department.

Stamp, G. E., Williams, A. S. \& Crowther, C. A. (1995) Evaluation of antenatal and postnatal support to overcome postnatal depression: a randomised controlled trial. Birth, 22, 138-|43.

Stern, D. (1995) The Motherhood Constellation. New York: Basic Books.

Stuart, S. \& O'Hara, M. W. (1995) Interpersonal psychotherapy for post-partum depression. Journal of Psychotherapy Practice and Research, 4, 18-29.

Wickberg, B. \& Hwang, C. (1996) Counselling of postnatal depression: a controlled study on a population based Swedish sample. Journal of Affective Disorders, 39, 209-216.

Zhang, J. \& Yu, K. F. (1998) What's the relative risk? A method for correcting odds ratio in cohort studies of common outcomes. Journal of the American Medical Association, 280, 1690-1691. 